\title{
It takes two to tango
}

\section{Decision-making processes on asset return}

\section{Claudia Baez-Camargo}

Gretta Fenner

Saba Kassa 
Basel Institute on Governance Working Paper 24. ISSN: 2624-9650.

(C) Basel Institute on Governance, October 2017

Responsibility for the views expressed and for any errors of fact or judgment rests with the author alone. 


\section{It takes two to tango Decision-making processes on asset return}

Claudia Baez-Camargo

Gretta Fenner

Saba Kassa 



\section{Table of contents}

\section{EXECUTIVE SUMMARY 7}

\section{INTRODUCTION 9}

2. DIALOGUE ON ASSET RETURN AND END-USE

2.1 When and how to initiate a dialogue 10

2.2 Who to engage in a dialogue 10

2.3 Why engage in a dialogue 11

2.4 Key takeaways 12

\section{SAFEGUARDING SOVEREIGNTY}

3.1 Safeguarding the sovereignty of the requesting state 13

3.2 Balancing sovereignty of the requesting and requested states 13

3.3 Key takeaways 15

\section{DECISIONS ON END-USE 16}

4.1 Considerations informing the end-use of returned assets 16

4.2 What modalities for managing and protecting returned assets? 16

4.3 Key takeaways 18

\section{OUTCOMES OF RETURNING STOLEN ASSETS}

5.1 Returning assets for the benefit of requesting governments and their citizens 19

5.2 Key takeaways 21

\section{CONSIDERATIONS FOR A GUIDANCE ON ASSET RETURN 22}

6.1 Functionality of further guidance 22

6.2 Parameters for further guidance 22 



\section{Executive Summary}

This working paper presents findings from a research project that sought to better understand decision-making processes on the return of illegally obtained assets using the examples of past cases of returning assets that had been stolen from Kazakhstan, Peru and the Philippines. While previous papers on the subject of returning stolen assets and end-use of returned assets were based on third party and desk research, the research feeding into this working paper is based on firsthand accounts collected through semi-structured interviews with key decision makers involved in these cases in the concerned states (see Annexes I and II for methodology and interview questionnaire). A preliminary analysis of these interviews and subsequently a draft version of this report were presented for discussion and validation during two separate expert workshops, in December 2016 in Bern, Switzerland, and February 2017 in Addis Ababa, Ethiopia, respectively.

The key objective of the research was to better understand the motivations, considerations and processes that led to the decisions on how and for what purpose to use returned assets. In this context, the report in particular looks at a question often debated in asset recovery circles, namely whether there may be a power imbalance between requesting and requested states in these processes despite the fact that requesting states are legally empowered through the UN Convention against Corruption (UNCAC). The potential existence of such a power imbalance has in the past often given rise to concern, as it is perceived to potentially compromise the fundamental principles of asset return of UNCAC and the sovereignty of the concerned states.

In a nutshell, the research summarised in this report found that that while power imbalances have been observed, though to varying degrees depending on the case and the combination of concerned states, this has in practice not negatively affected the actual asset return process in the analysed cases. The research has also found that such imbalances are by no means always one-sided or negatively tilted toward the requesting state. More important seems to be the existence of a shared interest among concerned states, which was usually found in the fundamental objectives of returning assets swiftly and invest them in such a way that a matter of public interest is advanced. In this regard, from the perspective of the requesting states, recovering the funds and defining an end-use that either redresses the victims, addresses the root causes of the original crime, or contributes in another meaningful way to social and economic development in the country, was understood to send a strong message of commitment by the government to the public good and to the fight against impunity for corruption. From the perspective of the requested states, returning these funds is typically considered important as harbouring illicit money is a threat to their financial systems and contributes to international financial crime with its wide ranging negative impacts on the global economy and development. As such, the concerned parties typically share an interest in returning stolen assets and in preventing renewed use of these funds for illegal purposes. Thus, the idea of concerned states jointly discussing the modalities for returning stolen funds and their end-use may give rise for concern about potential power imbalances, a demonstrated pursuit of the same outcomes has in practice helped overcome these concerns.

Succeeding in this move away from concerns about power imbalance to a discussion of shared objectives would however, as our research has shown, depend on a host of practical considerations and the willingness of all concerned states to enter into a constructive dialogue that takes into account the perspectives of requesting and requested states. Deserving equal attention are the substantive issues that arise when it comes to defining the precise modality of asset return. Although it seemed to have been comparatively easy to come to identify a purpose for which returned assets should be used that is in line with the shared objectives in returning stolen assets, challenges seemed to arise in the process of identifying and developing the precise modalities through which this purpose is effectively achieved. In addition, the research demonstrates that context matters greatly and that another critical element is the careful consideration not only of the purpose toward which returned assets should contribute and the related implementation mechanism, but also the potential need for associated policy and monitoring instruments. Adequate deliberation about the technical 
aspects that will govern the transfer and use of recovered funds helps to build trust and enhance cooperation.

In view of the findings of this report summarised in the above paragraphs, it is suggested that developing guidance for the dialogue between concerned states in the context of returning stolen assets may be a key to depoliticise the nature of the engagement, support all concerned parties in the process, help manage expectations and facilitate an alignment of the actors involved around a common vision. Such guidance may act as neutral mediation tools in support of building up the cooperation of all stakeholders towards the successful return of assets, providing a framework for dialogue that builds trust without undermining sovereignty, legal rights and obligations of any of the parties and offering actionable insights on the way the process is best managed and implemented. 


\section{Introduction}

Decision-making processes for the return of stolen assets engage with one of the more normative dimensions of asset recovery. The United Nations Convention against Corruption (UNCAC) establishes that illegally obtained assets should be returned to its original legitimate owners. Although this is the core principle of the Convention, it subsequently provides only general guidance on how the return and end-use of such assets may be done: In Article 57.5. UNCAC provides that state parties - where appropriate-could consider concluding agreements regarding the final disposal of the assets (UNODC, 2004: 48). While the Convention engages with the legal and technical context of asset recovery and creates an opening for different structures of engagement between state parties, the practice informs that these processes also have clear political dimensions. The political dimensions often revolve around the normative aspects of sovereignty, underscoring the particularly delicate nature of dialogues between state parties when it comes to financial matters and questions of responsibility for international financial crime. So far, these political sensitivities have made attempts to generate a commonly accepted guidance, guidelines or standards for returning and using returned stolen assets difficult.

Considering the aforementioned - and inspired by the Addis Ababa Action Agenda, which encourages the development of good practices on asset return - this report seeks to make a contribution to this topic by analysing the decision-making processes that led to the return of stolen assets in cases involving Kazakhstan, Peru and the Philippines (on the side of the so-called "requesting states"), and the concerned states from where the assets were to be returned ("requested states"). The arguments made in this report are substantiated by research involving interviews with key actors who were personally involved in the negotiations. Attempts to also include in the study the experience of Nigeria in relation to returned assets stolen by former President Sani Abacha unfortunately failed due to difficulties in receiving inputs from concerned parties. Prior to finalising this report, the underlying research findings have been presented to and discussed with expert audiences at two occasions, including at the Swiss Public International Law Day in December 2016, and at an international expert workshop on asset management and return, in February 2017 in Addis Ababa, Ethiopia.

Primarily, the report aims to further the understanding on the considerations taken into account by requesting and requested states to engage in a dialogue to define the precise terms for the return and end-use of illegally obtained assets (Chapter 2), and related questions around the critical issue of sovereignty in these dialogues (Chapter 3). Additionally, the report identifies issues to be considered in determining, ideally in a dialogue between concerned states, the modalities of end-use of and safeguarding stolen assets (Chapter 4). It also discusses some of the strengths and weaknesses of the outcomes of the different return modalities and end-uses adopted in the cases studied seen from the perspective of the interviewees (Chapter 5). On the basis of this information, the report makes the argument that there is much to be learned from these asset recovery processes, and in particular from first hand involved persons, and that these insights can be the basis upon which to consider the potential usefulness of more structured forms of engagement between state parties in the form of a guidance (Chapter 6). 


\section{Dialogue on asset return and end-use}

\subsection{When and how to initiate a dialogue}

The UNCAC establishes that stolen assets, once confiscated, should be returned to their prior legitimate owners. To operationalize this principle, the state parties involved in the case studies analysed in this report engaged in a dialogue. These engagements typically commenced not just after the confiscation was confirmed, but already during the initial stages of the asset recovery process, i.e. when assets were detected and frozen.

The usefulness of engaging in a dialogue at quite an early stage of the asset recovery process has been particularly highlighted by interviewees involved in the cases on behalf of Peru and the Philippines. In Peru the early engagements between the Swiss and Peruvian authorities allowed the latter to explain the local case context and express their desire to repatriate the assets in the shortest time possible and initial thoughts on end-use. In addition, it allowed the parties to engage in a discussion on the identification of the origin of the funds and establish the manner in which these had been transferred from Peru to Switzerland. Having the opportunity to meet in person and by cooperating with the Swiss authorities, the Peruvian officials were also able to engage with the formal procedures of the asset recovery process, while at the same time, supporting the case for a final restitution process. Besides this, their early engagements also provided both parties an opportunity to establish a relationship upon which they could build trust and develop an agreement on the end-use of assets, which was to be to advance national development objectives and strengthen the fight against corruption. Interviewees confirmed that the trust created through this early engagement allowed the parties to jointly identify and pursue the most flexible and fast approach to returning the assets to the Peruvian authorities.

As noted above, early engagement between state parties also proved useful in the case of the Philippines. Interviewees noted in this context the absence, initially, of a
Mutual Legal Assistance (MLA) Treaty, which made it necessary to break new grounds for the Philippine authorities to commence a dialogue with their Swiss counterparts. It was noted that once the Treaty was in place and allowed for the parties to engage in a formal dialogue, the process was expedited. The treaty was instrumental in providing guidance on how collaboration in this process could take shape, although this guidance was primarily focused on the legal procedures and not related to decision regarding the end-use of returned assets. At the same time, interviewees remembered that early engagement between state parties specifically geared toward discussing the end-use of eventually returned assets had been viewed as risky by some, as it was feared the defendants could raise accusations of collusion or of attempting to influence an on-going legal processes. These considerations were also relevant in the case of Kazakhstan.

\subsection{Who to engage in a dialogue}

In terms of the actors involved in these processes and dialogues on the side of requesting states, in the cases analysed these were predominantly the ministries of justice and foreign affairs as well as the involved prosecuting and judicial authorities and sometimes the lawyers representing the requesting countries in the requested states and legal proceedings there. In the case of Kazakhstan, the Prime Minister's Office, the Ministry of Justice and the Kazakh Ambassador in the USA and lawyers representing the Kazakh Government in the USA were important actors in the process. In the case of the Philippines, it was the Office of the Ombudsman and the Departments of Justice and Foreign Affairs that played a leading role. In the case of Peru - according to one interviewee due to the very special political situation that existed at the time - the law enforcement agencies played a dominant role. In particular the Office of the Attorney General and the Judge presiding over the cases had been engaged directly with the Swiss authorities.

On the side of the requested states, similar organs were involved in the dialogue. In the case of Switzerland, it was 
the typically Federal Department of Foreign Affairs and the State Secretariat for Economic Affairs that took a lead role in the processes, while in the United States, the Department of Justice usually had a lead role, with inputs from the State Department and occasionally other law enforcement agencies and foreign missions. In the case of Kazakhstan, the World Bank was included in the discussions, represented through the Offices of the President and the Vice President. The World Bank was said to have agreed to this role also because it provided an opportunity to contribute to anti-corruption activities, which in turn supported its on-going poverty alleviation activities in Kazakhstan. This was later formalised in the decision of the Southern District Court making the involvement of the World Bank legally binding to all state parties. Bringing in a third, neutral party into the dialogue was considered a desirable strategy to facilitate a dialogue between states that do not have a strong history of such dialogue or may even be conflicting over other matters.

Although it might be easy to imagine the various parties representing the requesting and requested states at different ends of the table, interviewees stated that these dialogues were usually mostly operational and often quite collaborative. For instance, in the case of the Philippines, the Swiss government provided support on the drafting of the procedures of the law that detailed the compensation of the victims of human rights abuses under the martial law. In other cases too, and despite the asymmetrical nature of the relationship between requesting and requested states, early and cooperative engagement was perceived as conducive to harnessing the expertise available in the requested state in support of the restitution processes to the requesting state. This may be particularly helpful when the domestic institutions in the requesting state are limited in their capacity to handle grand corruption cases. In Peru at the time for example, there was very limited infrastructure in place to handle asset recovery processes; by way of example the country did not yet have a financial investigation unit. In this case, this resulted in the provision of a team from the Federal Bureau of Investigation (FBI) to support Peruvian authorities in their domestic investigations and providing a direct point of contact within the US Department of Justice.

\subsection{Why engage in a dialogue}

As noted earlier, and in particular when such a dialogue is started early on in the process of recovering stolen assets, all interviewees considered that dialogue between concerned states had been beneficial for expediting the process, both during the legal proceedings and in the final stages of returning and defining the end-use of returned assets. A key factor contributing to this was clearly the fact that time allows to build trust, which in turn was key when it came to resolving the potentially most sensitive matter, namely the modalities for returning and using the returned assets.

Interviewees stated that by engaging in a dialogue, the parties could establish an initial agreement that guided the ensuing discussions. They also experienced that the dialogue was essential in ensuring that interests of all parties in the asset recovery process were understood and could be taken into account. For instance, in the case of the Philippines, the parties were able to find common ground early on in the idea that the recovered assets should be used (amongst others) to redress victims of human rights abuses under the martial law, and to support agricultural reform. Because of this early agreement, assets were returned even before the end of the legal process and placed in an escrow account pending the fulfilment of a number of modalities established by the Swiss Federal Court, such as the passing of legislation in the Philippines that determined that the assets would be used to redress human rights victims. This had a significant positive impact in the Philippines, akin to what was stated by an interviewee from Peru as a key impact of asset recovery, namely “(...) a positive moral blow for the country and a very clear message to the corrupt that everything possible will be done to deprive them of those assets which have been obtained illicitly."

It is clear that requesting and requested states each come with their own motivations, objectives and interests to the discussion, but interestingly interviewees found that often they converged more than deferred. One interest that is usually always converging is that of moving swiftly. Whereas successful return of stolen assets sends a strong message 
in the requesting state that corruption will not remain unpunished, it sends an equally strong signal by the requested state that its financial system will not be a conduit for illegal assets. The parties can also rally behind a common vision that is articulated through the end-use, for example redress for victims or support to national development which ultimately also highlights the fundamental principle of the UNCAC, emphasising that corruption has a corrosive effective on societies; undermines democracy, the rule of law, violates human rights, distorts markets, erodes quality of live and allows threats to human security to flourish (UNODC, 2004: iii). Indeed the global recognition of these fundamental principles in the UNCAC and in subsequent international texts is likely to further enhance the convergence of interests in asset return discussions.

\subsection{Key takeaways}

- (Early) engagement between concerned states can facilitate and potentially expedite the asset recovery process including discussions on end-use of returned assets

- (Early) engagement helps build trust and supports building a common vision of the ultimate objective of asset recovery

- Requesting states may use the dialogue as an opportunity to harness expertise residing within the requested states to facilitate the asset recovery processes

- An MLA treaty can provide guidance for how to engage in a dialogue

- While each party has its own motivations and objectives when engaging in dialogue, a number of these often converge, most notably the interest in a swift return of stolen assets and the interest in using the asset return to send signals domestically. 


\section{Safeguarding sovereignty}

\subsection{Safeguarding the sovereignty of the requesting state}

Dialogue between requesting and requested states on modalities for returning stolen assets have the potential to be contentious, to a large extent due to the fact that both parties have legitimate interests at stake. A critical aspect that comes up in this debate concerns safeguarding the sovereignty of the requesting state. Although it was clear that the sovereign right to determine the end-use of the returned assets resides with the requesting state, interviewees stated that this issue was more relevant at a political level and much less relevant at the operational level.

Most interviewees stated that while the sovereignty of the requesting state was a topic present in the background of the political dialogue between the parties, it was not openly addressed. The reason for these concerns appearing to be less relevant in practice were attested to the fact that mostly it was considered a foregone issue once the dialogue had started, as starting a dialogue would not have been possible without the consent of both states. In the case of the Philippines, the absence of an MLA Treaty made the requesting party proactively reach out to the Swiss government for support. The concern was thus more with the absence of a legal framework for collaboration than protecting sovereignty. In the case of Peru, the issue of return and end-use was perceived as an ever-present topic in bilateral discussions between Peru, Switzerland and the United States, as such these discussions were not seen under the label of sovereignty but under the label of bilateral (and multilateral) relations and joint anti-corruption efforts.

In the case of Peru, the inclusion of an element of a consultative process reaching beyond the state sphere is particularly interesting. At the recommendation of the United States, the Peruvian government conducted a so-called "notice and comment" system, through which it publicly announced and asked for comments on the manner in which the returned assets would be utilised. The notice and comment system in Peru was considered valuable in managing societal expectations. By bringing in civil society perspectives and participation in these decision-making processes, it was possible to harness their support and concerns at an early stage. This also served as a strategy to pre-empt possible critiques on the content of the chosen modality during its implementation stage, while the final decision remained in the hands of the government. Peruvian interviewees interpreted this process as a testimony to the acknowledgement that while sovereignty is to be preserved, a dialogue-based outcome is likely to be better accepted by all concerned parties.

Thus, our research suggests that while protecting the sovereignty of the requesting state is a critical aspect of asset recovery, at the operational level pragmatic considerations have proven to be more relevant. An interesting thought was raised by one of the interviewees in relation to the case of Kazakhstan:

Sovereignty is more discussed in policy meetings, not so much in the discussions on specific cases. Sovereignty is only a theoretical issue. Sovereignty anyway resides in the people not in the government, so how do you get the money back to the people and make sure people have a role in the use of the money? That is the bottom line. In that sense, it is about ensuring that the actual sovereign - the people can decide and benefit.

\subsection{Balancing sovereignty of the requesting and requested states}

This more pragmatic approach adopted by state parties may be facilitated by the wish to pursue specific goals related to the asset return process. This was particularly relevant in the case of Kazakhstan, where the recovered assets concerned the proceeds of bribery and the desire by the requesting state to protect the reputation of the government alongside some pressures from foreign parties influenced the nature of the dialogue. These dynamics were further impacted by the US Southern District Court decision, which 
made a number of stipulations regarding the end-use, such as that the funds should not be returned directly to the Kazakh government but be utilised to enhance the social good and be disbursed by a third party with involvement of the World Bank. The fact that the Court could decide in such detail on the return modalities is unique in this case as the assets were confiscated in the context of a settlement; as such the issue of sovereignty is less at stake under the applicable international legal frameworks. The level of concessions made in this particular case was higher on the side of the Kazakh government, whilst it can be argued that their reputational gains may balance this out, as well as the fact that ex post evaluations of the project that was eventually implemented with the returned assets has benefited the Kazakh society considerably.

The asset return process in the Philippines was also dominated by a pragmatic approach. Here the absence of an MLA Treaty and indeed any applicable international legal framework made the engagement with the Swiss authorities contingent on the goodwill of the Swiss authorities to facilitate these processes and return the assets to the Philippines. The converging interests described in the previous chapter, of the Philippines to receive the assets swiftly, and of Switzerland to set a sign against misuse of its financial centre, have supported the discussions and allowed to find agreement rather quickly. The risk of the returned assets being misappropriated again was an important topic during the discussions according to one interviewee who stated:

The Swiss government was concerned that the returned assets would be stolen or otherwise used improperly again. I think these were reasonable concerns given the level of corruption in the Philippines at the time. They were also concerned about the developmental and social impact that the underlying crime had had on the Philippines, and so was my Government.

Indeed, it was a shared interest of the Philippine and Swiss state parties that the assets should be returned swiftly but with the joint understanding that it would be critical that these funds would not be stolen again. Both parties also agreed that the returned assets should be employed to make up for some of the above quoted developmental and social damages and human rights abuses that resulted from corruption under the Marcos regime. By framing the concerns as such, it was possible for both parties to acknowledge (tacitly) the validity of concerns about the integrity of the modality for end-use, while taking away the politically sensitive sting of discussing such issues more openly and as a judgement or reflection on the capabilities of the Philippine government. As such, the primary concern of the Swiss government was that a substantial amount of the returned funds would be used to compensate the human rights violations victims of the Marcos regime and a result placed two related modalities on the return of recovered funds.

The acknowledgement by the Philippines that the concerns of the Swiss government were reasonable and valid also resonated through in the case of Peru. Here the parties were also in agreement over the need for Peru to return what was lost while considering the need for ways to disburse the funds that would be protected against renewed malpractices. In this regard, the explicit political will conveyed by the transitional government and newly elected government in Peru at the time were key factors that expedited this agreement. To this end, one interviewee stated:

It is understandable that states like the United States and Switzerland had their doubts that these funds would be well invested due to the corruption background of Peru. This sort of tension is natural but I would not say that in the Peruvian case there really was a conflict because of that.

This is not to say that agreement was always immediate. Peru and the United States for example were said to have disagreed on the proposal by the latter to channel a portion of the recovered assets to the flight against drug trafficking. In the end, such politically sensitive issues were however typically overcome by framing them within a pragmatic discourse that led to mutually acceptable modalities of engagement and collaboration. From a comparative perspective, the concessions made by the concerned states seemed to have been more balanced in the cases of the Philippines 
and Peru, whilst as noted above in the case of Kazakhstan a certain imbalance must be observed, partially attested to the particular nature of the applied confiscation regime. In both Peru and the Philippines, the dialogue was said to have been open and collaborative, and interviewees from all concerned states stated that the joint wish to expedite the asset return resulted in an agreement that was cognisant of the wishes of the requested state while following the interests of the requesting state and local context. An interviewee from Peru summarised this pointedly as follows:

In weak countries with corrupt structures entrenched in the highest echelons of power something that cannot happen is that you make an effort to recover or repatriate all these assets and that they return to corruption schemes. Thus, if the international community - not of course because of a whim or by imposition or other political motivations or otherwise, but based on a healthy concern to see that these funds are well invested in favour of the communities of the requesting states - suggests that dialogue is a good practice for determining asset return and end-use, I am totally in favour of being able to create a dialogue to reach reasonable and positive agreements.

\subsection{Key takeaways}

- The dialogue between parties on the modalities for returning stolen assets and their end-use may be influenced by a power imbalance between concerned states, though it can indeed be to the advantage of either the requesting or requested states, and the power constellation strongly varies from case to case.

- This power imbalance may give rise to concerns about sovereignty, but these concerns are in practice most prevalent in political discussions and less so at operational level where pragmatic considerations prevail.
- Power imbalance and concerns about sovereignty have in practice most effectively been overcome by willingness by all concerned parties to acknowledge shared objectives in the asset return process.

- These shared objectives are in turn framed within the joint design of modalities for returning and using returned stolen assets.

- By acknowledging shared interests and using them to guide the design of modalities for return and end-use of stolen assets, the concerned parties can avoid more politically charged discussions which would be deviated by power imbalance. 


\section{Decisions on end-use}

\subsection{Considerations informing the end-use of returned assets}

The end-use of returned assets is one of the critical pinnacles of the asset recovery process. As such, the government of the requesting state closes the corruption loop in that it recovers public funds that were illegally misappropriated. To ensure that the asset recovery process, which often takes many years to complete due to the complex technical and legal nature of this process, comes to a truly successful end, many interviewees found that assigning the returned assets to a particular purpose has important symbolic implications, many of which have been discussed in earlier sections. In practice, numerous criteria have been applied to determine the particular use for returned assets, and these criteria are invariably very context sensitive. Criteria applied in the discussed cases include the nature of the underlying crime, the impact of the crime (victims) or the identity of the perpetrator of the crime, although the case of Kazakhstan stands out in this regard as noted later.

In the case of Peru, the nature of the crime through which the assets were misappropriated was the key factor that informed the end-use of the return assets. According to relevant interviewees, the decision to not dilute the assets in the general budget but rather for them to be used for an "altruistic" purpose, and specifically to address weaknesses in the country's anti-corruption system, was quickly taken. According to interviewees involved in the Peruvian case, these ideas were supported by a majority of international non-governmental organisations that contacted the concerned states in this regard.

In the case of the Philippines, the impact of the underlying crime was a key consideration informing the decision on the end-use of the returned assets, as a result of which it was agreed that the returned assets should be used to compensate the victims (of human rights abuses under the martial law of former President Marcos which was fuelled by corruption). In related cases in the Philippines, consideration was also given to the peasant farmers who suffered from the land reforms implemented under the martial law and where corruption under Ferdinant Marcos had generated a considerable share of the stolen funds. In sum, the main concern was to ensure that the money went back to those that suffered most under the Marcos regime.

In the case of Kazakhstan, case related considerations were less relevant as the recovered proceeds were the result of alleged bribery and the assets were returned as a result of a settlement. Instead, it was considered important to utilise the funds in such a way that it would address key economic and social needs of the Kazak citizens, thereby acknowledging the fact that corruption is internationally recognised to harm social and economic development. Indirectly this can be seen as a consideration of impact of the underlying crime, although less directly than in the case of the Philippines. Interviewees also reiterated that considerations of transparency in the utilisation of funds, indirectly a reference to the underlying crime as per the Peruvian example, as well as issues of absorption capacity due to the fact that funds were not to be administered by the Government, were importantly considered.

\subsection{What modalities for managing and protecting returned assets?}

Modalities to manage and use returned assets can have various designs and are particularly informed by the objectives of the end-use and characterised by the extent to which the government of the requesting state is in control of these processes. On the one hand, assets can be returned to the government and integrated into the regular budget, utilising the ordinary public financial management systems to monitor the fund disbursement. In practice this could mean fully merging the returned funds into the national budget or including it in the national budget but earmarked to a particular budget line. A variant on this is what is often referred to in dedicated literature as "enhanced country system", in which case additional precautions are expected to be taken in order make the asset management and 
disbursement more transparent. Alternatively, arrangements could be made for the creation of a dedicated and typically autonomous fund with enhanced public reporting and accountability arrangements. Another option is the transfer of fund management and disbursement responsibility to a third party, such as an international or non-governmental organisation. (World Bank 2009: 11) In one case of assets that were returned from Switzerland to Angola (not discussed in this report), the funds were returned through a program implemented by Switzerland's bilateral aid agency (Swiss Agency for Development Cooperation, SDC).

In the case of Kazakhstan, the concerned state parties together with the World Bank agreed that the recovered assets were to be managed through an autonomous fund called the Bota Kazakh Child and Youth Development Foundation (Fenner Zinkernagel \& Attisso, 2014: 340). This new institution had to be created specifically for facilitating the return of the assets due to the fact that no local (non-governmental) organisation had been found that seemed to have sufficient absorption and implementation capacity, and the ruling of the US Southern District Court prohibited the return of the funds directly to the Government. Following an international procurement processes, the International Research and Exchanges Board (IREX) was selected to build the structure and capacity of the Bota Foundation. The Bota Foundation was staffed primarily with Kazakh citizens and overseen by a board of trustees composed of five Kazakh citizens and one representative each from Switzerland and the USA. The creation of a Foundation dedicated exclusively to the return of stolen funds from the US and Switzerland allowed to create particular control and oversight functions, as a result of which according to interviewees no significant incidents of theft or misuse of these funds occurred; according to one interviewee only one instance of a (comparatively small) misuse of funds was detected and could be remedied immediately.

In the Marcos case, the assets were transferred in early 2004 from Switzerland to an escrow account with the Philippines National Bank, but were to remain frozen on that account until a number of stipulations made by the Swiss
Federal Court were met. Amongst these were that a third of the returned assets were to be used to compensate victims of human rights violations committed during the martial law; the remainder was largely to be used for agrarian reform, in response to the fact that the agriculture sector was thought to have suffered particularly much from corruption under the Marcos regime. The law establishing this arrangement and the ad hoc specialised body that was to administer the funds for the purpose of human rights violation compensation, the Human Rights Victims' Claims Board, was eventually passed in 2013. The 10-year delay in passing the law has given rise to great concern among the interviewees and outside observers, as the redress for human rights victims will in many cases now come too late, as stated by one interviewee. Also, a number of allegations were made regarding the use of the funds that were to be used for agricultural reform, as other reports have described (e.g. World Bank 2007).

In the case of Peru, the assets returned from Switzerland and the United States were channelled through a national fund (FEDADOI), which however was administered through the normal budget with a board of representatives determining the allocation of the funds. The board was composed of representatives of five government agencies, and as part of the agreements between returning and requesting states, the assets were to be invested in anti-corruption efforts (Fenner Zinkernagel \& Attisso, 2014: 335-336). Indeed, the set-up and implementation of FEDADOI was such that an enhanced scrutiny over the destination and end-use of funds was possible, including to a degree by civil society, and that projects were to be funded that would directly benefit the rule of law and the fight against corruption. In addition, the concerned funds would undergo the standard controls implemented by the Peruvian Ministry of Economy and Finance as part of the country's public financial management system. Interviewees from Peru have admitted that some of the projects funded through this arrangement were potentially questionable, and that the involvement of the heads of potential beneficiary agencies in the decision making over the use of funds could have been perceived as a conflict of interest. 


\subsection{Key takeaways}

- The end-use of returned funds has in practice typically been linked to the origin of the assets, and notably to either the nature of the underlying crime, the impact of the underlying crime, or the nature of the perpetrator(s) of the underlying crime.

- Irrespective of which of these options is chosen, linking the end-use to an aspect of the origin of the stolen crimes is considered to have great symbolic meaning, as it is a way to make up for the damages caused by the underlying crime and/or to show resolve against the underlying crime.

- The objective of the end-use of returned assets informed the modalities through which these assets would be managed.

- Various designs have in the past been used to manage and protect the returned assets, with varying degree of government influence in the administration of the fund, and varying degree of success in protecting the returned funds from further misuse. 


\section{Outcomes of returning stolen assets}

\section{1 Returning assets for the benefit of requesting governments and their citizens}

The different modalities adopted for the end-use of returned assets in the country case studies were well considerate of the political context of implementation and, as noted in the previous section, focused primarily on efforts to either compensate for damages caused by the underlying crime or working towards reducing and preventing such crimes from occurring again. From an anti-corruption perspective, in which asset recovery is deeply enshrined, and from the perspective of development, of which anti-corruption is an important component, these returns can therefore be considered a success. However, and despite the comprehensive discussions that preceded the various modalities, the implementation has been quite challenging and outcomes limited at times. This section attempts to take stock of these past experiences with a particular focus on some of the weaknesses and failures of the utilised arrangements, not in order to discredit the largely positive outcome but rather to ensure that future end-use designs may benefit and become more effective based on this experience.

When considering the case of Kazakhstan, a quite comprehensive autonomous foundation was set-up to disburse the recovered assets. Of all the different modalities that could have been considered, this arrangement had the least amount of government influence. This being said, although on paper the influence of the government was limited, many of the projects would not have been implemented without the assistance and tacit support of the government. This resulted in a positive outcome in that at least one of the project components was later considered for adoption into general government policy, but implementation did suffer occasionally from the limited interaction with and thus support from the Government. Another point to consider was that the Foundation had a fairly comprehensive governance and oversight structure. According to subsequent evaluations of the project, this was instrumental in preventing misuse of funds. Interviewees however stated that the arrangement had been criticised because around $10 \%$ of the returned funds were used for the administration of the project. It would appear however that when compared to regular overhead rates applied to technical assistance projects, this is an acceptable cost and adequate in light of the benefits of having successfully safeguarded the project from a considerably high risk of re-misappropriation of the funds.

As a takeaway from the Kazakhstan experience, one could imagine that the sustainability of the outcomes would have possibly been stronger if a local organisation had been found with sufficient absorption and implementation capacity or, in the absence of such a capable organisation, if the project had teamed up with an emerging local organisation to carry forward the work after the funds had been used up. Moreover, interviewees were of the opinion that although the projects chosen for financing with the returned assets were of great significance to the concerned population, utilising at least some of the returned assets to support anti-corruption and anti-money laundering efforts would have had an even greater symbolic effect and long-term impact.

The importance of giving due consideration to the modality chosen is also exemplified in the case of the Philippines. Although the recovered assets were returned to the treasury and an escrow account, respectively, disbursing the funds has taken significant delays. The design of the enduse was thoughtful and meaningful as it reflected strongly on the causes that have led to the funds being stolen in the first place, but operationalizing the mechanism proved to be complex. There continues to be disagreement in the Philippines' parliament on the manner in which the funds should be disbursed and the manner in which legitimate claims by victims should be identified; these matters were never really clearly defined during the discussions on return and end-use. Of course the provision for parliamentary scrutiny is to be viewed positively as it may allow for adequate monitoring; this may compensate to a point for the lack of involvement of civil society groups, despite the presence of a strong and vocal civil society in the country. However, debate and potentially politically motivated and interest driven contest over the manner in which the assets should be disbursed 
has created serious bottlenecks to the effective implementation. Interviewees stated also that there were numerous concerns raised regarding corruption in the procedure as a result of gaps in the latter. As put forward by one of the interviewees from the Philippines:

Hence, the devil is in the details. In theory, the way the end-use was designed for the returned funds stolen by former President Marcos was meaningful and good, but the practical implementation posed major problems and continues to do so, which may easily result in the purpose being largely defeated.

A different set of challenges arose in Peru where the parameters and management of the fund were well designed and had a clear symbolic significance, conveying a sincere wish of the government to seek to prevent future such crimes from occurring. This was described by one of the interviewees from Peru as follows:

It was significant in terms of the message and the destination. It had a positive impact on recipients whom it seems to me were well chosen as priorities by the state.

To this end, an initial list of beneficiaries was developed which determined how FEDADOI would disburse the funds. However, challenges arose when the power struggle over access to these funds erupted in the context of political changes. In one instance, a new Minister introduced changes to the rules governing how FEDADOI funds were to be used. When a new government took power, further changes were made that attracted criticism from civil society and other stakeholders. The lesson to be learned from this example is that it is important to consider the political context in which modalities are implemented and, more importantly, how a change in this context could influence the end-use of the agreed modality. The case of Peru shows well how even only small and incremental changes diluted the initial purpose and meaning of the fund, which ultimately created a situation in which it was possible to use the fund to cover current government expenses rather than for the objectives defined in the asset return discussions.
The cases of Peru and the Philippines showed how a well thought through mechanism for use of the recovered assets can run into difficulties during operationalization. Considering these two challenges, interviewees from both countries considered that an alternative arrangement could have been to manage the recovered assets within a completely independent fund and to entrust the administration of the fund to a neutral third party, or to place stricter requirements on the utilisation of the recovered assets. As an interviewee from the Philippines stated:

Perhaps a completely independent fund could have prevented some of these problems, but this would have also been an admission on the side of the requesting and requested government that there is a lack of good faith in the administration. It is for this reason that both the requesting and requested states need to be honest about corruption concerns and capacity constraints. Otherwise, the returned assets will be badly invested due to bad management or even lost to corruption again.

This indicates that there is some kind of trade off involved in the manner in which the dialogue between the requesting and requested states ensues and the subsequent operationalization of the modality designed for the end-use of recovered assets. Indeed, the issue of trust and showing good faith in the engagements between the state parties has an important symbolic meaning to support progress in the discussions. However, more critical scrutiny regarding the precise nature of modalities and possible challenges that may arise in their implementation also need to be taken seriously, and should not be sacrificed for the benefit of a swift or over-harmonious dialogue. At the end of the day, detailing the various safeguards to ensure an effective utilisation of the returned assets is in the interest of both parties. Furthermore, by framing these issues within a context where general guidance to the discussion around return and end-use is available, state parties would possibly be able to better balance the more delicate relational aspects of the process and at the same time be cognisant of the need to establish appropriate modalities to govern the end-use of returned assets. 
Although the different modalities for asset return have encountered various challenges, it is clear that none of the associated benefits would have been sustained should the money had gone back without making provisions for its end-use. Beyond the risk of losing the returned assets again through corrupt vehicles or alternatively, absorbing the funds within the general budget, the effort of returning assets would have also missed out on its potential symbolic impact and political message. This political message associated with the return of assets could be considered as important as the monetary value associated with the recovered assets itself.

\subsection{Key takeaways}

- The implementation of the different modalities adopted for the end-use of returned assets in the cases studied has had considerable impact in terms of furthering development, preventing corruption or rectifying harm done by the underlying crime, but their implementation has met several challenges.

- Consideration should be given to the feasibility of the end-use mechanism, as exemplified by the challenges faced in the Philippines with the human rights compensation scheme.

- Consideration should be given to the sustainability of any social and economic impact that end-use schemes are intended to have.

- A thorough operationalization of the design needs to consider the local political context, including how a change in that context could affect the end-use.

- (Independent) monitoring facilities may assist in managing these processes and simultaneously act as a risk-mitigating strategy.
- Dialogue between requesting and requested states can provide a framework in support of developing effective and efficient modalities governing the end-use of returned assets; challenges that may occur in this dialogue should not prevent a careful reflection on feasibility and details of end-use implementation mechanisms. 


\section{Considerations for a guidance on asset return}

\subsection{Functionality of further guidance}

Guidance developed by and for both requesting and requested states must first and foremost confirm the fundamental principles of returning stolen assets and the sovereignty of concerned states. Its main contribution, however, would be in reducing unnecessary politicisation of the debate by anchoring the discussion for large parts at the operational level. As such, the debate can be geared toward the objectives over which states in the past have typically found consensus, namely: that assets should be returned swiftly; that they should be used to advance a public good; and that the sovereign rights of the requesting state must be respected whilst the investments made by requested state must equally be recognised. A potential power imbalance, which in any event is not always to the disadvantage of the same side as noted earlier, can be contained if the discussion is framed in a neutral mediation tool, such as a guidance note, which allows parties to address their respective concerns in a constructive manner.

A guidance note may also support the institutionalisation of good practices regarding structured engagements between state parties and reflections regarding feasible and meaningful mechanisms for end-use and factors that could be considered in identifying shared objectives and determining such end-use, as such making a repeated discussion of the political aspects of the debate in each case increasingly unnecessary. The bottom line is that these are highly complicated and delicate processes. The purpose of a guidance note is not to disguise these or pretend that everything can be managed at a purely technical level. But by relying on an internationally accepted guidance, state parties can pursue their interests by reflecting on previous experiences with asset recovery processes that are systemised in various considerations and parameters.

\subsection{Parameters for further guidance}

As the cases studied in this report have clearly shown that there is no one single best practice when it comes to the return and end-use of stolen assets. It is therefore important that any attempt to develop guidance does not seek to reflect a prescriptive agenda but instead offers a set of parameters to consider when determining end-use of returned assets, over which concerned states can align their interests and objectives and ensure that local and case related context is taken into account. In this regard, and drawing from the experiences recounted in this report, the following matters would appear to be worth including for consideration in a guidance:

\section{Define stakeholder composition:}

- Which stakeholder(s) should be involved in the determination of these objectives in the requesting state? Which agency/ies will lead the discussions on behalf of the requested states? Defining this from the beginning will greatly enhance communication and efficiency.

- Would involving a third party (e.g. international organisations, independent expert(s), civil society) be useful to act as facilitator for the dialogue on end-use?

\section{Define objective(s) of end-use, e.g.:}

- Redress victims (specific groups of citizens or institutions, or the society at large, a particular sector, a particular region, etc.);

- Deal with the root cause(s) of the crime(s) that led to the dissipation of the assets, e.g. by strengthening national anti-corruption efforts or institutions or policies;

- Broader developmental goals as per the requesting state's national development plan which are potentially unrelated to the case at hand; 


\section{Operationalisation of asset return modality:}

- Absorption capacity (often depending on the amount of assets concerned)

- Role of executive power, other government entities (including autonomous bodies), civil society or other third parties in the implementation

- Definition of a detailed implementation plan

- Likelihood and potential impact of changes in the political context on implementation

\section{Monitoring and accountability:}

- What type of accountability mechanism could be considered adequate in relation to amount involved and risk patterns identified?

- What accountability mechanisms exist that could satisfy this need within the requesting state?

- Is it advisable and desirable to provide for enhanced scrutiny over the use of returned (formerly stolen) funds?

- What is the role of international, national and societal monitors (i.e. parliament, civil society, international actors), if any? 


\section{References}

Fenner Zinkernagel, G. \& Attisso, K. (2013) "Past experience with agreements for the disposal of confiscated assets." in: Emerging Trends in Asset Recovery, Peter Lang AG.

Jimu, I. (2009). Managing Proceeds of Asset Recovery: The Case of Nigeria, Peru, the Philippines and Kazakhstan. Working Paper Nr. 06. Basel Institute on Governance. Available from: https://www.baselgovernance.org/sites/collective. localhost/files/publications/biog_working_paper_06.pdf

UNODC (2004) United Nations Convention Against Corruption. New York. Available from: http://www.unodc. org/documents/treaties/UNCAC/Publications/Convention/08-50026_E.pdf

World Bank (2007). Stolen Asset Recovery (StAR) Initiative: Challenges, Opportunities and Action Plan. Washington D.C., World Bank. Available from: http://www.unodc.org/pdf/ Star_Report.pdf

World Bank (2009) Stolen Asset Recovery. Management of returned assets: Policy considerations. Washington D.C., World Bank. Available from: https://www.unodc.org/documents / corruption/Publications/StAR/StAR_Publication_-_ManagementReturnedAssets.pdf

\section{Annex I Methodology}

This report is informed by insights gained from semi structured interviews conducted with key officials that were personally involved in the decision-making processes in the cases of Kazakhstan, Peru and the Philippines, both on the sides of the requesting and requested states. The interviews were instrumental in providing further contextual insights and to shed light on factors that influenced how the concerned states interacted and which choices were made in relation to the end-use of returned assets and accountability arrangements.

The statements made by interviewees have purposefully been anonymised in this report in consideration of the delicate processes and outcomes of asset recovery. When the report describes the process or reflections that were made by the concerned parties in this context, this is always based on explicit responses to questions given by the interviewees. The interpretation of these statements as given in this report on the other hand, unless otherwise stated, are those of the authors of this report.

The interviews were conducted by senior staff of the Basel Institute and under the overall strategic leadership of the Director of the International Centre for Asset Recovery. 


\section{Annex II Interview questions}

\section{Introductory question}

1.1 What was your position and role in the dialogue leading to the decision making process on asset return and their end-use?

\section{Engaging in a dialogue on asset return}

2.1 At which point of the restitution process did your country consider engaging in a dialogue on asset return?

- What were the main motivations to engage in the dialogue?

\section{Actors involved in the dialogue on asset return}

3.1 Who were the key actors and what was their position or role in the dialogue on the side of your country?

3.2 Which other actors or partners played an important role in this process?

3.3 How did such partners become engaged?

\section{Dialogue on end-use of returned assets}

4.1 Were there are any concerns about safeguarding the sovereignty of the receiving country? If so, how were these taken into account during the dialogue?

- Was there an open discussion about such concerns?

4.2 Which particular concerns were raised by the requested states? How were these taken into account during the dialogue?

4.3 What was the primary interest of the requested state in the dialogue in your opinion?

- Was there an open discussion about these interests?

4.4 How did the key considerations in the scope of the dialogue change over time? What were the reasons for this?

- What were the most important concessions made by each party?

4.5 How do you see the balance arising out of the concessions made by the parties?

4.6 Which significant exogenous factors influenced the dialogue?

- Did other bilateral topics influence the dialogue? If so, how?

- Was reference made (explicitly or implicitly) to another dossier of asset return? If so, could you explain on how this occurred?

4.7 What were the most important considerations that ultimately led to the choice of this particular end-use of the returned assets?

- Identity of the victims resulting from the crime

- Characteristics of the perpetrator

- The networks associated with illicitly obtaining public funds were still in power

- Nature of the crime associated with the recovered funds

- Amount of money involved

- National development priorities

- Concerns about the performance of the public financial management system

4.8 Were these discussions held in a private multilateral or bilateral setting or discussed in public settings (such as Parliament).

4.9 How did you manage expectations both internally and externally?

- Were there any arguments appealing not to engage in this particular choice of end-use of the funds?

- Which office or actor did they come from?

- How were these concerns countered or dealt with? 


\section{End-use of returned assets}

5.1 Which different options of end-use were contemplated and what were the decisive criteria for the particular choice made?

5.2 How was the decision made on who would be in charge of implementing the chosen modality of end-use?

\section{Implementation of agreed modality for the end-use of returned assets}

6.1 Which were the main challenges encountered during the implementation of the modality associated with the end-use of the returned assets?

6.2 Which were the main challenges in the process of monitoring the correct execution of the end-use of the retuned assets?

- How and for how long did the monitoring take place?

- Was there a follow-up?

\section{Outcomes of the agreed modality for the end-use of returned assets}

7.1 In hindsight, do you think that the chosen modality for the end-use of returned assets has been meaningful? If so, could you please give examples of this?

7.2 Alternatively, do you believe there could have been a different and better approach taken? If so, could you please give examples of how an alternative approach would have been more appropriate?

7.3 In your opinion, what would have been the impact should the assets have been returned directly into the treasury?

8. Policy implications

8.1 Do you believe that the development of guiding principles on dialogues for the return and end-use of returned assets would be helpful? (or would have been helpful to you?)

8.2 In your opinion, what would be the key parameters that such guiding principles should take into account? 


\section{Basel Institute on Governance}

The Basel Institute on Governance is an independent non-profit competence centre specialised in corruption prevention and public governance, corporate governance and compliance, anti-money laundering, criminal law enforcement and the recovery of stolen assets. Based in Switzerland, the Institute's multidisciplinary and international team works around the world with public and private organisations towards its mission of combating financial crime and tangibly improving the quality of governance globally.

\section{International Centre for Asset Recovery}

The International Centre for Asset Recovery (ICAR) was founded in 2006 as a specialised division of the Basel Institute on Governance. Within the Basel Institute's mission, ICAR pursues the goal of supporting affected jurisdictions to investigate and prosecute financial crimes and cooperate with other jurisdictions for this purpose, with the ultimate aim of recovering stolen public assets.

ICAR achieves this goal through training, casework, legal and policy analysis, the development of integrated IT tools, and active contributions to the global policy dialogue and international standard setting in asset recovery. ICAR receives core and project specific contributions from the Principality of Liechtenstein, the Swiss Development Cooperation and the UK Department for International Development, and project specific grants from a variety of other international and bilateral cooperation partners.

\section{Working papers}

In this working paper series the Basel Institute on Governance publishes reports by staff members and invited international experts, covering critical issues of governance theory and practice. For a list of publications, please visit www.baselgovernance.org. 


\section{CONTACT}

Basel Institute on Governance

Steinenring 60

4051 Basel, Switzerland

www.baselgovernance.org

info@baselgovernance.org

ISSN: 2624-9650

\section{Abstract}

This working paper presents findings from a research project that sought to better understand decision-making processes on the return of illegally obtained assets using the examples of past cases of returning assets that had been stolen from Kazakhstan, Peru and the Philippines. While previous papers on the subject of returning stolen assets and end-use of returned assets were based on third party and desk research, the research feeding into this working paper is based on first-hand accounts collected through semi-structured interviews with key decision makers involved in these cases in the concerned states.

The key objective of the research was to better understand the motivations, considerations and processes that led to the decisions on how and for what purpose to use returned assets. In this context, the report in particular looks at a question often debated in asset recovery circles, namely whether there may be a power imbalance between requesting and requested states in these processes despite the fact that requesting states are legally empowered through the UN Convention against Corruption (UNCAC). The potential existence of such a power imbalance has in the past often given rise to concern, as it is perceived to potentially compromise the fundamental principles of asset return of UNCAC and the sovereignty of the concerned states. 